\title{
Genetic divergence for seedling and qualitative traits of tomato (Solanum lycopersicum) germplasm
}

\author{
Salma Anjum ${ }^{1 *}$, Abdul Hamid ${ }^{1}$, Abdul Ghafoor ${ }^{2}$, Raja Mohib \\ Muazzam Naz ${ }^{1}$, Kashif Khaqan ${ }^{1}$, Muhammad Aqeel ${ }^{3}$ and Muhammad \\ Ilyas $\mathrm{Khan}^{4}$ \\ 1. Department of Horticulture, Faculty of Agriculture, University of the Poonch, Rawalakot, Azad Jammu \& \\ Kashmir-Pakistan \\ 2. National Agricultural Research Centre (NARC), Islamabad-Pakistan \\ 3. Pakistan Agricultural Research Council (PARC), Islamabad-Pakistan \\ 4.Department of Plant Breeding and Molecular Genetics, University of the Poonch,Rawalakot,Azad Jammu \& \\ Kashmir-Pakistan \\ *Corresponding author's email: salmaanjum.upr@gmail.com \\ Citation \\ Salma Anjum, Abdul Hamid, Abdul Ghafoor, Raja Mohib Muazzam Naz, Kashif Khaqan Muhammad Aqeel \\ and Muhammad Ilyas Khan. Genetic divergence for seedling and qualitative traits of tomato (Solanum \\ lycopersicum) germplasm. Pure and Applied Biology. Vol. 9, Issue 1, pp776-789. \\ http://dx.doi.org/10.19045/bspab.2020.90084
}

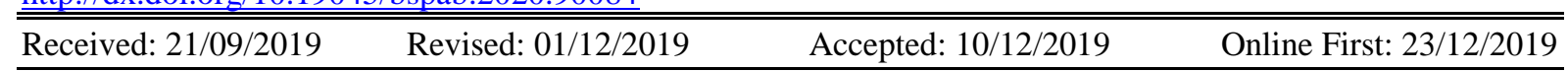

\section{Abstract}

One hundred and eighty-five tomato genotypes were explored for seedling and qualitative characters of tomato fruits and plants. Significant variations were detected for all studied traits. Hypocotyl length (HL) ranged from 13.2 to $71.4 \mathrm{~mm}$ with a mean value of $40.86 \pm 0.86$. Primary leaf length (PLL) showed the range from 12.1 to $42.3 \mathrm{~mm}$. Primary leaf width (PLW) ranged from 3.2 to $12.1 \mathrm{~mm}$ and the mean value was $6.46 \pm 0.12$. Among qualitative analysis, eighty percent of genotypes showed good health. Various qualitative traits (fruit shape, color and size, foliage density and leaf type) for vegetative and reproductive stages were sufficient to differentiate the tomato germplasm in addition to seedlings. Dendrogram based on qualitative traits (fruit and plant) of 185 genotypes of tomato germplasm comprising five main clusters. Germplasm comprised almost all the classes reported somewhere else demonstrating prime diversity for diverse qualitative traits of seedlings in the germplasm of tomato preserved in the gene bank excluding hypocotyl pubescence. The present study of the seedling will be helpful with qualitative data of fruit and plant for establishment of the core set in providing information about the study of morphological evaluation, genetic relationships and representation of genetic diversity.

Keywords: Genetic divergence; Germplasm; Qualitative traits; Seedling; Tomato accessions

\section{Introduction}

Tomato (Solanum lycopersicum L.) belongs to a Solanaceae family that comprises more than three thousand species of tomato. It is a significant vegetable crop grown in the fields or greenhouses have distinctive economic position around the world in the horticultural industry $[1,2]$. is a diploid species and has $2 n=2 x=24$ chromosomes. The haploid genome of tomato species has 12 chromosomes and genome size equivalent to $950 \mathrm{Mb}$ about $77 \%$ of which is heterochromatin and $23 \%$ euchromatin [3]. Tomato ranks second most important vegetable crop, and as a result of the robust breeding program, it has 
wider adaptation and is being cultivated all over the world after potato [1].

Tomato has globally achieved the position of the most widely used vegetables because of its multipurpose uses, better adaptability and extensively studied crop with respect to genomics, genetics and breeding [4]. Lycopersicon esculentum var. cerasiforme (cherry tomato) is thought to be an ancestor of cultivated tomato based on its wide presence in tropical America [5]. As a domesticated crop, it was first accepted in America though the innovative places of domestication are unclear [6]. Mexico has accepted a most likely site of domestication with Peru as a center of diversity for wild relatives [7]. It is self-pollinated fruit berry represent low to moderate genetic diversity due to bottlenecks in the germplasm of cultivated tomato, particularly in Europe [8, 9]. Tomatoes are grown on 3.7 million hectares in the world with a total production of around 100 million tones [10]. China being the top producer (34 million tons), followed by USA (12.7 million tons) and Pakistan is at the 34th position in fresh tomato production with annual production is 575,923 tons [11]. Tomatoes and their products are popular nutritive food and continue to increase because they are a good source of minerals, vitamins and antioxidants [12].

Tomato is a short-lived perennial but usually grown as annuals throughout the world. It is a member of the Solanaceae family and a highly self-pollinated plant. The cultivated tomato has gained popularity very rapidly in world food crops and attained the status of most consumed vegetables in the world [13]. It is understood that tomato is native to South America, the Incas and Aztecs began cultivating tomato plants as early as 700AD [14]. Genetic evidence shows that the progenitors of tomatoes were herbaceous green plants with small green fruit and a center of diversity in the highlands of Peru [15]. It is believed that tomato is introduced by British colonists at the beginning of the 19th century in the region of Indo-Pak [16].
The lumpy tomato, a larger mutation from a smaller fruit, smoother, originated in Mesoamerica and may be the direct ancestor of some modern cultivated tomatoes [17].

Assessment of the intra-population genetic variability in tomato has been reported important by Mazzucato et al. [18]. These authors analyzed morphological and molecular descriptors in Italian landraces of tomato. Seedling traits give an indication for plant growth and could also be used as plant descriptors as well as markers. Monogenic traits were the first to be employed for varietal identification and for markers which are still important for most of the crops $[19,20]$. he seedling qualitative descriptors have been utilized for the identification of various crop varieties and as genetic markers for investigation of quantitative traits loci $[21,22]$. The present study was initiated to characterize tomato germplasm for seedling traits and qualitative traits of tomato fruit and plants to investigate the magnitude of diversity among genotypes and clusters. This data will serve the purpose of genotypic identification and later will be utilized for establishing core collection to have the maximum diversity in less number of genotypes.

\section{Materials and methods}

The study was conducted to assess the genetic diversity of tomato germplasm on the basis of seedlings and qualitative traits of fruit (Fig. 1). One hundred and eightyfive genotypes of tomato germplasm included 150 genotypes from Solanum lycopersicum (L.) and 33 genotypes from Solanum lycopersicum var. cerasiforme and two check varieties Sahil and Roma. A research study conducted in green and shade house of Bio-resources Conservation Institute (BCI) NARC, Islamabad, Pakistan One hundred and eighty-five accessions of tomato were obtained from the National Gene Bank, BCI (NARC) Islamabad, Pakistan. Field experiments were carried out at NARC and nursery was raised in the green-house. The seeds were sown in 
plastic pots on 15 February during 2016 and the pots were kept in the greenhouse at $25^{\circ} \mathrm{C}$ and irrigated with the help of sprinkler at alternate days, or when required. Onemonth-old seedlings were transplanted with the layout of Augmented Design in the shade-house. Each genotype was planted in two rows keeping $75 \mathrm{~cm}$ row spacing and $50 \mathrm{~cm}$ plant spacing in the shade-house (130 feet length, 30 feet width) at Crop Science Institute (CSI), NARC, Islamabad. Sahil and Roma (check varieties) were repeated after every 20 rows of genotypes.

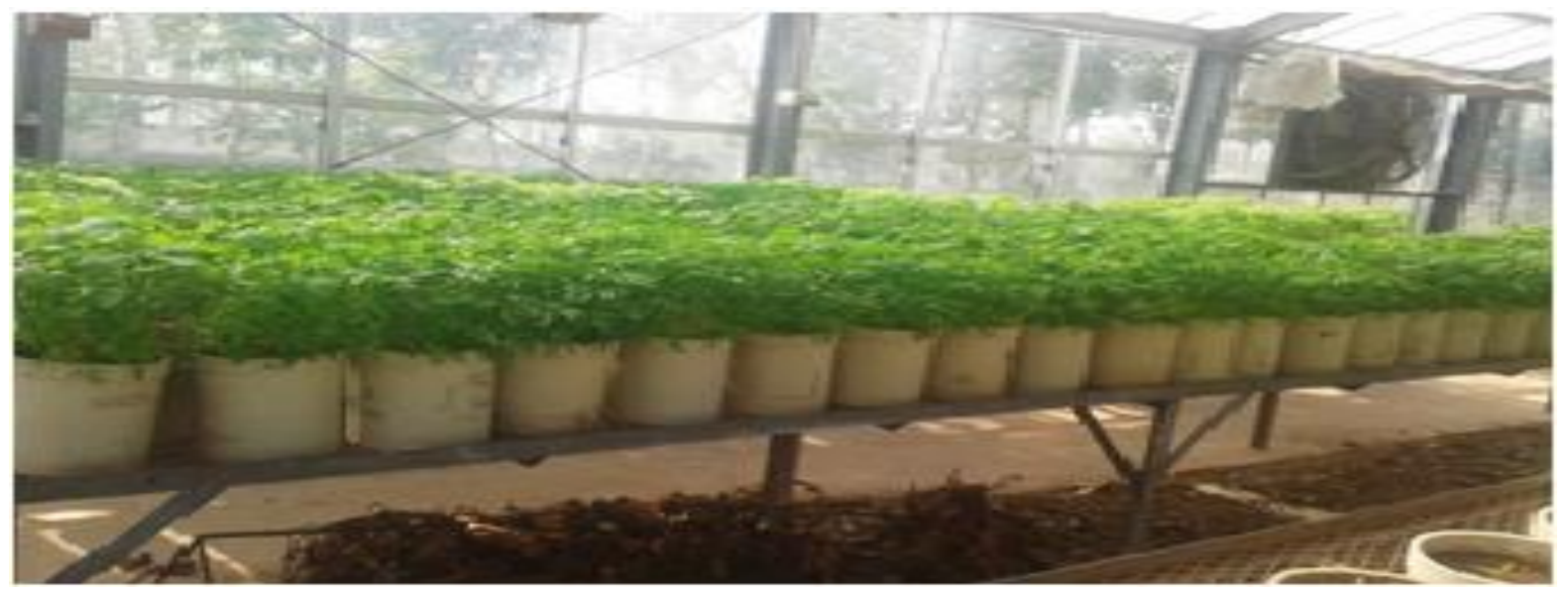

Figure 1. Seedlings of 185 genotypes of tomato germplasm

\section{Characterization at Morpho- physiological level}

All the genotypes were evaluated at the seedling stage for 5 qualitative (Hypocotyl color, hypocotyl color intensity, pubescence on hypocotyl, overall leaf color, seedling vigor) and 3 quantitative (Primary leaf length, leaf width, Hypocotyl length) characters (Table 1). Data were recorded for seedling traits by following the descriptor of tomato established by the International Board for Plant Genetic Resources [23]. For the seedling stage, qualitative data (hypocotyl color, the intensity of color and pubescence density) were recorded after the development of the first two leaves. Other discrete traits including seedling vigor and overall color of leaf were also noted on genotype basis, hence represent single value for each genotype however quantitative traits, viz., hypocotyls length $(\mathrm{mm})$, primary leaf length $(\mathrm{mm})$ and primary leaf width $(\mathrm{mm})$ were recorded on average of ten seedlings selected randomly from each genotype.

Plant characters were recorded in the shadehouse after seven weeks of transplantation. The qualitative traits (Table 2) included stem pubescence density, foliage density, number of leaves under the first inflorescence, leaf type, leaf attitude, exterior color of immature fruit and stem internode length were recorded whereas, data for exterior color of mature fruit, fruit size and fruit shape were recorded at fully ripened stage.

\section{Statistical analysis}

Descriptive statistics (mean, standard error, standard deviation and range) were computed for all seedling traits and frequency distribution for qualitative traits to estimate the genetic diversity present in the germplasm of tomato. The dendrogram was constructed for morphological qualitative traits based on the dissimilarity matrix by the un-weighted pair group of arithmetic means analysis (UPGMA) [24]. Analyses were carried out using the $\mathrm{R}$ software.

\section{Results and discussion}

Tomato germplasm comprised of a total of 185 accessions along two check varieties (Roma and Sahil) were investigated for genetic variations. The genetic base of tomato varieties is narrow, which makes it difficult to identify different varieties using 
molecular markers. Even though morphological analysis is the first step, however, better presentation is expected when coupled agronomic traits with molecular markers in various crop analysis [25].

Quantitative and qualitative parameters were studied for seedlings, plants and tomato fruits evaluation. Quantitative traits comprised of hypocotyl length, primary leaf length and primary leaf width at the seedling stage were presented in the (Table 3) Data for hypocotyl pubescence, hypocotyl color, color intensity, leaf color and seedling vigor at the seedling stage were presented in (Table 4) according to data descriptors presented in (Table 1).

Table 1. Descriptors key (IBPGR 1996) used in estimation of diversity at seedling stage of tomato germplasm

\begin{tabular}{|c|c|c|c|}
\hline \multicolumn{2}{|c|}{ Descriptors } & \multirow[t]{2}{*}{ Symbols } & \multirow[t]{2}{*}{ Scale } \\
\hline \multicolumn{2}{|c|}{ Seedling qualitative descriptors* } & & \\
\hline \multicolumn{2}{|c|}{ Hypocotyl color } & $\mathrm{HC}$ & $\begin{array}{c}\text { 1-green, 2- 1/4 purple from base, } 3-1 / 2 \\
\text { purple from base, } 4 \text { - purple }\end{array}$ \\
\hline \multicolumn{2}{|c|}{ Hypocotyl color intensity } & HCI & 3-low, 5- Intermediate, 7-High \\
\hline \multicolumn{2}{|c|}{ Hypocotyl pubescence } & $\mathrm{HP}$ & 0- Absent, 1-Present \\
\hline \multicolumn{2}{|c|}{$\begin{array}{c}\text { Overall leaf color } \\
\text { Seedling vioor }\end{array}$} & OLC & 1-low, 3- intermediate, 5- dark \\
\hline Seedling & & SV & 1- good, 2- weak \\
\hline \multicolumn{3}{|c|}{ Seedling Quantitative Descriptors } & \\
\hline Primary leaf length & PLL & $\mathrm{mm}$ & Average of 10 cotyledonous leaves \\
\hline Primary leaf width & PLW & $\mathrm{mm}$ & Average of 10 cotyledonous leaves \\
\hline Hypocotyl length & HL & $\mathrm{mm}$ & $\begin{array}{l}\text { Average of } 10 \text { hypocotyls measured from } \\
\text { soil surface to level of cotyledonous leaf. }\end{array}$ \\
\hline
\end{tabular}

Data for seedling recorded after development of first two leaves

Table 2. Descriptors key (IBPGR 1996) used in characterization of qualitative traits of fruit and plant of tomato germplasm

\begin{tabular}{|c|c|c|}
\hline Plant descriptors*(Qualitative) & Symbols & Classes \\
\hline Stem pubescence density & SPD & 1- Dense, 2- Sparse \\
\hline $\begin{array}{c}\text { Stem internode length } \\
\text { Foliage density } \\
\text { No. of leaves under the first } \\
\text { inflorescence }\end{array}$ & SIL & 1- Intermediate, 2-Long, 3- Short \\
\hline Leaf attitude & NLFI & 1- Dense, 2- Intermediate, 3- Sparse \\
\hline Leaf type & LA & 1- Many, 2- Few, \\
\hline Fruit descriptors* & 1-Drooping, 3- Semi-erect,7- Horizontal, \\
\hline Exterior color of immature fruit* & ECIF & $\begin{array}{c}\text { 1-hirsutum, 2-pimnelifolium, 3-potato leaf, } \\
\text { 4-standard }\end{array}$ \\
\hline Fruit size & FS & $\begin{array}{c}\text { 3- Medium (5.1-8 cm), 4- large (>8 cm), 5- } \\
\text { small (3-5cm) }\end{array}$ \\
\hline Exterior color of mature fruit & ECMF & $\begin{array}{c}\text { 2-Black red, 5- orange, 7- pink, 9- red, 10- } \\
\text { Verigated red, 11- yellow, }\end{array}$ \\
\hline Fruit shape* & FS & $\begin{array}{c}\text { 1- Ellipsoid, 2- cylindrical, 3- flattened, 4- } \\
\text { heart-shaped, 5- rounded }\end{array}$ \\
\hline
\end{tabular}

Legends: Data for plant descriptors* were noted when the fruits of 50\% were ripened. Data for fruit descriptors* were noted at the fully mature stage of fruits. Data for the exterior color of immature fruit*were noted before maturity. Fruit shape* were noted after the fruits turn color

Table 3. Means with standard error, range, standard deviation and variance for seedling traits 


\begin{tabular}{|c|c|c|c|c|}
\hline Traits & Mean \pm SE & Standard Deviation & Range & Variance \\
\hline Primary leaf length $(\mathrm{mm})$ & $27.60 \pm 0.45$ & 6.15 & $12.1-42.3$ & 37.82 \\
\hline Primary leaf width $(\mathrm{mm})$ & $6.46 \pm 0.12$ & 1.61 & $3.2-12.1$ & 2.58 \\
\hline Hypocotyl length $(\mathrm{mm})$ & $40.86 \pm 0.86$ & 11.73 & $13.2-71.4$ & 137.49 \\
\hline
\end{tabular}

Table 4. Frequency distribution of qualitative variables for the seedling of tomato germplasm

\begin{tabular}{|c|c|c|}
\hline Traits & Classes & Frequency \\
\hline \multirow{4}{*}{ Hypocotyl color } & Green & 0 \\
\cline { 2 - 3 } & One fourth purple from base & 46 \\
\cline { 2 - 3 } & Half purple from base & 58 \\
\cline { 2 - 3 } & Purple & 81 \\
\hline \multirow{3}{*}{ Hypocotyl color intensity } & Low & 42 \\
\cline { 2 - 3 } & Intermediate & 63 \\
\cline { 2 - 3 } & High & 80 \\
\hline \multirow{2}{*}{ Hypocotyl pubescence } & Absent & 0 \\
\cline { 2 - 3 } & present & 185 \\
\hline \multirow{3}{*}{ Overall leaf color } & Low & 23 \\
\cline { 2 - 3 } & Intermediate & 138 \\
\cline { 2 - 3 } & Dark & 24 \\
\hline \multirow{2}{*}{ Seedling vigor } & Good & 148 \\
\cline { 2 - 3 } & Weak & 37 \\
\hline
\end{tabular}

\section{Seedling stage}

The data for seedling traits were recorded in the greenhouse. The results for quantitative traits are presented in (Table 3). Hypocotyl length (HL) ranged from 13.2 to $71.4 \mathrm{~mm}$ with a mean value of $40.86 \pm 0.86$ and a standard deviation of 11.73. Primary leaf length (PLL) showed the range from 12.1 to $42.3 \mathrm{~mm}$. The mean value with standard error for the character was $27.60 \pm 0.46$ whereas, the standard deviation was 6.15. Primary leaf width (PLW) ranged from 3.2 to $12.1 \mathrm{~mm}$ and the mean value was $6.46 \pm 0.12$ while the standard deviation was 1.61 . The variance was a maximum of 137.49 for hypocotyl length tailed by primary leaf length (37.82) and a minimum of 2.58 was recorded for primary leaf width.

The qualitative traits regarding seedling vigor, hypocotyl pubescence, color and color intensity were analyzed and the results are presented in (Table 4). Hypocotyl color was noted at the seedling stage with all categories. Green hypocotyl was not observed in any genotype. Hypocotyl with purple color was scattered into three classes. Accessions with hypocotyl one-fourth purple from the base were 46 with a frequency of $24 \%$ while half purple hypocotyl was observed in 58 accessions with a frequency of $31 \%$ in germplasm. However, complete purple hypocotyl was observed in 81 accessions with the highest frequency of about $43 \%$. Hypocotyl color intensity was investigated low for $22 \%$ (42 accessions) of the germplasm. High color intensity was recorded 34\% in 63 accessions whereas, 80 accessions depicted intermediate color intensity i.e. $43 \%$ of the germplasm (Table 4). Hypocotyl pubescence exhibited no variation, hence all the germplasm showed pubescence characteristics. Twenty-three genotypes exhibited light leaf color with 12 $\%$ frequency of the germplasm and the same percentage was noted for dark green color. However, the highest frequency was 74\% noted in 138 accessions having an intermediate color. An important trait is seedling vigor that was observed high in 148 genotypes ( $80 \%$ frequency) of the germplasm whereas, seedling vigor was detected weakly in 37 genotypes, i.e., 
nearly about 20 percent. The seedling vigor is predominantly important for tomato improvement, hence the genotypes with better seedling vigor are suggested to use in the breeding program either for hybridization or through direct selection [26].

A major threat to conservation and adaptive potential in the genomic development of crop species is a loss of genetic diversity that has tremendous experiences during the last century [27]. Various gene banks are available for ex-situ conservation for research purposes globally, with enormous accessible genetic resources of tomato. For effective and efficient germplasm evaluation, collection and utilization assessment of genetic diversity and interactions between germplasm are important [28]. Basic evidence along with significant development in tomato has been reported worldwide [29]; however, this crop has not much researched in Pakistan. Crop improvement depends on the accessibility of information on morphological data and plant descriptors along with the level of diversity [30].

Keeping in view the importance of tomato in daily consumers' life, and the constraints of less research work conducted in Pakistan, the present study was initiated to evaluate a broad-based genetic stock for morphological evaluation with economic importance. Previously genetic variation was detected in all characters except stem pubescence studied by Rizvi et al. [31] who investigated the genetic diversity of three hundred and eighty accessions for nine seedling traits of tomato and concluded that spectrum of exploitation will be improved by the characterization/ evaluation of germplasm for various characters. The present study will be helpful in providing information about the study of morphological evaluation, genetic relationships and representation of genetic diversity. Germplasm comprised almost all the classes reported somewhere else demonstrating prime diversity for diverse qualitative traits of seedlings in the germplasm of tomato preserved in the gene bank excluding hypocotyl pubescence. Characterization of tomato genotypes, their wild relative's presence or absence of pubescence on fruits and vegetative parts has been used as a morphological trait [32]. The morphological evaluation of tomato hypocotyl has been used to detect the homozygous or heterozygous nature of tomato germplasm for mutant [33]. Monogenic characters were the first to be employed and they are still important for markers and varietal identification for most of the crops [19, 20]. Six traits were of discrete nature out of nine seedling characters and may likely to be unified as genotype identification in single or in combination [34].To predict plant health and growth, diversity for seedling vigor traits is also important. Qualitative traits of seedling have been employed as a genetic marker and for the identification of various crop varieties for the examination of quantitative traits loci $[21,35]$. The application of a seedling marker for the identification of hybrids resulted to lower down the expense of hybrid seeds [36].

\section{Qualitative traits of tomato plants and fruits}

Qualitative parameters were studied for morphological evaluation. The plant descriptors including stem pubescence density, number of leaves underneath the first inflorescence, stem internode length, foliage density, leaf type and leaf attitude were recorded and presented in (Table 5). Fruit descriptors included the exterior color of immature fruit, exterior color of mature fruit, fruit shape, size were displayed in (Table 6).

\section{Frequency distribution}

Stem pubescence density was a common characteristic of plants of tomato among various qualitative traits (Table 5). The frequency distribution of qualitative traits showed that germplasm was distributed into two classes based on pubescence density. In the first-class frequency of genotypes with the sparse pubescent stem (19 accessions) was 10\%. Highly dense 
pubescent stems $(89 \%)$ were observed in 166 accessions. Stem internode length exposed that short length of internode was characteristic of $42 \%$ of (79) accessions of tomato germplasm. Long internodes were $7 \%$ in 16 accessions however, $48 \%$ of the genotypes (90) were exhibited medium internodes. Sparse foliage density was observed in 26 accessions with a frequency of 14 percent. Genotypes having dense foliage were 77 i.e. $41 \%$ of germplasm while $44 \%$ of the germplasm (82 accessions) represented medium foliage density.

Two categories of accessions were observed one with few and second with many leaves under the first inflorescence. The majority of the accessions (155) had many leaves with a frequency of $84 \%$ whereas 34 accessions had few leaves with a frequency of $18 \%$ of germplasm. It was observed that different categories for leaf attitude were horizontal, semi-erect and drooping. The majority of genotypes (86) were horizontal with the frequency of $46 \%$ population followed by drooping (82 genotypes; $42 \%$ ) and semi-erect leaf attitude with $9 \%$ population of 17 genotypes approximately. Leaf type trait was divided into 4 categories i.e. Standard leaf type was observed in the majority of accessions (147) with a total population of $79 \%$, followed by hirsutum in 22 accession $(12 \%)$ and 10 genotypes exhibited potato leaf type i.e. merely of $6 \%$ frequency of a total population. However, pimnellifolium leaf type was observed in 4 genotypes having a lower frequency of $2 \%$ of the total population.

Various degrees for the exterior color of immature fruits showed a wide range of variation with different levels of frequencies (Table 6). The majority of the genotypes (95) with a frequency of $51 \%$ had light green fruits while green fruits were observed with less frequency of $38 \%$ in 71 genotypes. Greenish white immature fruits were counted in 28 accessions with $15 \%$ frequency while dark green fruits were noted in 18 genotypes with a lower frequency of $10 \%$ population. Moreover, the germplasm revealed adequate divergence for fruit shape. Different fruit shapes were detected with different frequencies. The variation displayed in the size and shape of the fruit is presented in (Fig. 2).

Fruit size is an important trait in tomato that depends upon consumers' preference, in the genotypes evaluated, diverse fruit size was observed. Out of four classes as projected by IBPGR for descriptors of tomato only three were noted. Small-sized fruits (3.0$5.0 \mathrm{~cm}$ ) were produced by 38 genotypes with a frequency of $21 \%$. Large-sized fruits were produced by the majority of the genotypes (89) with a frequency of $48 \%$. Intermediate sized fruits $(5.1-8.0 \mathrm{~cm})$ were observed in 58 genotypes having a frequency of $31 \%$. For the exterior color of mature fruits, the germplasm was found uniform equally.

Majority of genotypes (148) produced red fruits with highest frequency $(79 \%)$ of population while, orange color fruit was observed in 21 genotypes (Juane Flamme, TH-15-103, TH-10-5-0021, TH-10-5-0043, Hongza No.16, Cherokee, Merit, Takiis Gem, Victoria Dwarf No.1, Master No. 2, Scoresby Dwarf, Latah, Burnely Fortune, Santa, Taturaa Dwarf Globe, YRF3, Accession 1369, Burneiy Gem, TH-100009, TH-10-0037 and Bulgaria) with a frequency of $11 \%$. Pink colored fruits were observed in 4 (Brandy Wine, Zhongza No. 4, W-C 1646 and S. Klave, Blagoevgrad) genotypes with $2.1 \%$ frequency and 9 accessions (Yellow Stuffer, Hillbilly Potato Leaf, Roman Candle, Yellow Round Tomato, Early Chatham, Li Cun, TH-100018, TH-10-0035 and TH-15-106were found having yellow colored fruits. Moreover, two accessions (Black Cherry, Black from Tula) produced blackish-red color and only one accession (Striped Cavern) exhibited variegated red-colored fruits.

Fruit shape also showed wide diversity in studied germplasm. Flattened shape fruits were recorded $11 \%$ of the germplasm (21 
accessions). Round fruit shape was noted in 150 genotypes having a frequency of $81 \%$ of total population. The genotypes with cylindrical, ellipsoid and heart-shaped fruits were less frequent, i.e. 11,2 and 1 accessions with frequencies of 6,1 and $0.5 \%$ percent, respectively.

Table 5. Frequency distribution of qualitative traits of the plant of tomato germplasm

\begin{tabular}{|c|c|c|}
\hline Traits & Classes & Frequency \\
\hline \multirow{2}{*}{ Stem pubescence density } & Dense & 166 \\
\cline { 2 - 3 } & Sparse & 19 \\
\hline \multirow{2}{*}{ Number of leaves under first infloresence } & Few & 34 \\
\cline { 2 - 3 } & Many & 151 \\
\cline { 2 - 3 } Leaf attitude & Horizontal & 86 \\
\cline { 2 - 3 } & Drooping & 82 \\
\cline { 2 - 3 } & Semi erect & 17 \\
\hline \multirow{3}{*}{ Leaf type } & Standard & 149 \\
\cline { 2 - 3 } & Hirsutum & 22 \\
\cline { 2 - 3 } & Pimnelifolium & 4 \\
\hline \multirow{3}{*}{ Foliage density } & Dense & 77 \\
\cline { 2 - 3 } & Sparse & 26 \\
\cline { 2 - 3 } & Intermediate & 82 \\
\hline \multirow{3}{*}{ Stem inter node length } & Intermediate & 90 \\
\cline { 2 - 3 } & Short & 79 \\
\cline { 2 - 3 } & Long & 16 \\
\hline
\end{tabular}

Table 6. Frequency distribution for qualitative traits of fruit in tomato germplasm

\begin{tabular}{|c|c|c|}
\hline Traits & Classes & Frequency \\
\hline \multirow{4}{*}{ Color of immature fruit } & Green & 71 \\
\cline { 2 - 3 } & Greenish white & 28 \\
\cline { 2 - 3 } & Light green & 95 \\
\cline { 2 - 3 } & Dark green & 16 \\
\hline \multirow{4}{*}{ Color of mature fruit } & Red & 148 \\
\cline { 2 - 3 } & Pink & 4 \\
\cline { 2 - 3 } & Yellow & 9 \\
\cline { 2 - 3 } & Orange & 21 \\
\cline { 2 - 3 } & Black red & 2 \\
\hline \multirow{4}{*}{ Size of fruit } & Variegated red & 58 \\
\cline { 2 - 3 } & Medium & 89 \\
\cline { 2 - 3 } & Large & 38 \\
\cline { 2 - 3 } & Small & 21 \\
\hline \multirow{4}{*}{ Shape of fruit } & Flattened & 150 \\
\cline { 2 - 3 } & Round & 11 \\
\cline { 2 - 3 } & Cylindrical & 2 \\
\cline { 2 - 3 } & Heart shape & 1 \\
\cline { 2 - 3 } & Ellipsoid & \\
\hline
\end{tabular}


Table 7. Distribution of genotypes in clusters based on qualitative traits of tomato

\begin{tabular}{|c|c|c|}
\hline Clusters & No. of genotypes & Genotypes \\
\hline Cluster I & 62 & $\begin{array}{l}\text { Black Cherry, Principe Borghese, Brandy Wine, Delicious, Burgess } \\
\text { Stuffing, 6233, 17904, LA-1969A, LA-4285A, TH-15-095, TH-15- } \\
\text { 103, TH-15-114, TH-15-117, TH-10-5-0011, TH-10-5-0015, TH- } \\
\text { 10-5-0012, TH-10-5-0026, TH-10-5 0030, Bell Pepper Tomato } \\
\text { 2015, Sub-Arctic Cherry, Hongza No.16, Hongza No. 20A, W-C } \\
\text { 1653, W-C 1654, W-C 1656, W-C 1655, W-C 1658, W-C 1660W- } \\
\text { C 1659, W-C 1666, W-C 16661, W-C 16668, W-C16669, Merit, } \\
\text { Rhodade, Mountain Prince, Bowen m15, Merbein Monarch, Rey de } \\
\text { lops Tempranos, College Red, Bowen R3, Potentate APO-12, } \\
\text { College Challenger, Salad Special, Bowen M8, Rodade, Money } \\
\text { Maker,YRF1, Punhong (19842), Roma, Molokai, LA-0314, TH-15- } \\
\text { 099, TH-10-5-0020, W-C1642, W-C 1643, W-C 1645, W-C 1651, } \\
\text { W-C 2330, W-C2365 and Cherry II. }\end{array}$ \\
\hline $\begin{array}{c}\text { Cluster } \\
\text { II }\end{array}$ & 87 & $\begin{array}{l}\text { Hillbilly Potato Leaf, Juane Flamme, TH-15-108, TH-15-113, TH- } \\
\text { 15-116, TH-10-05-0009, TH-10-5-0039, Beef Tomato 2015, G } \\
\text { 28504, Zhongza No. 4, W-C 1657,W-C 16667, W- C1673, Vendor, } \\
\text { Cherokee, Hatif de Cologne, College Abundant, Oahu, Geraldton } \\
\text { Smmoth Skin, Stakeless, Florida, W-C 2404,W-C 2405, Big Girl } \\
\text { VF, Zhongza No. 6, Cra, B 147, Large Raste, Harvestvee, Early } \\
\text { Chatham, Rougr de marnande, yellow wattle, Burnley Bounty, } \\
\text { Daydream, Alton, Victoria Dwarf No.1, Kootenai, Master No. 2, } \\
\text { Scoresby Dwarf, Latah, Fire Steel, Yubily, Basketvee, Florida } \\
\text { 5,Tomato Grande Vermeiho,Taturaa dwarf globe, YRF3, } \\
\text { Bonnyvee, Accession 1369, Fukuju (large), Colonial, College crop } \\
\text { well, Hongza No.20, Castlemor ll, J Morgan EC6582, CC VMV } \\
\text { Florida 3, Burneiy Gem, Ponderosa,TH-10-5-0045, Red rock, } \\
\text { Bowen M5, Homestead (T3),TH-10-0004,TH-10-0038,TH-10- } \\
\text { 0044,TH-10-0007,TH-10-0009,TH-10-0037, CN-87, LA-4285, LA- } \\
\text { 1969,Tomato 0033,TH-15-097,TH-15-101,TH-15-104,TH-15- } \\
\text { 106,TH-15-107,WK 015, W-C 1644,W-C 1646,W-C 1647,W-C } \\
\text { 1649,W-C 2341, W-C 1665, Kazkemet 815, Preslav, S. Milanovo } \\
\text { and Shumen }\end{array}$ \\
\hline $\begin{array}{c}\text { Cluster } \\
\text { III }\end{array}$ & 5 & TH-10-5-0021, TH-10-5-0043, Tom 10, Burnely Fortuneand Santa \\
\hline $\begin{array}{l}\text { Cluster } \\
\text { IV }\end{array}$ & 9 & $\begin{array}{c}\text { Yellow Stuffer, Roman Candle, Striped Cavern, Yellow Round } \\
\text { Tomato, Li Cun,TH-10-0018, TH-10-0035, A. Kosta Perchev, } \\
\text { Vidin and S. Klave Blagoevgrad }\end{array}$ \\
\hline $\begin{array}{c}\text { Cluster } \\
\text { V }\end{array}$ & 22 & $\begin{array}{l}\text { Tomato 004, TH-10-5- 0005, Black from Tula, Cherokee purple, } \\
\text { Jersey Devil, LA-0314A, Bulgaria, TH-15-096, TH-15-109, TH- } \\
\text { 15-112, TH-15-115, Verigated Striped Tomato, TH-10-5-0044, W- } \\
\text { C 1670,W-C 1671,Takiis Gem, La Rochapes, Sadong (19850), TH- } \\
\text { 10-0013,TH-10- 0024, ST } 23 \text { and Sahil }\end{array}$ \\
\hline
\end{tabular}

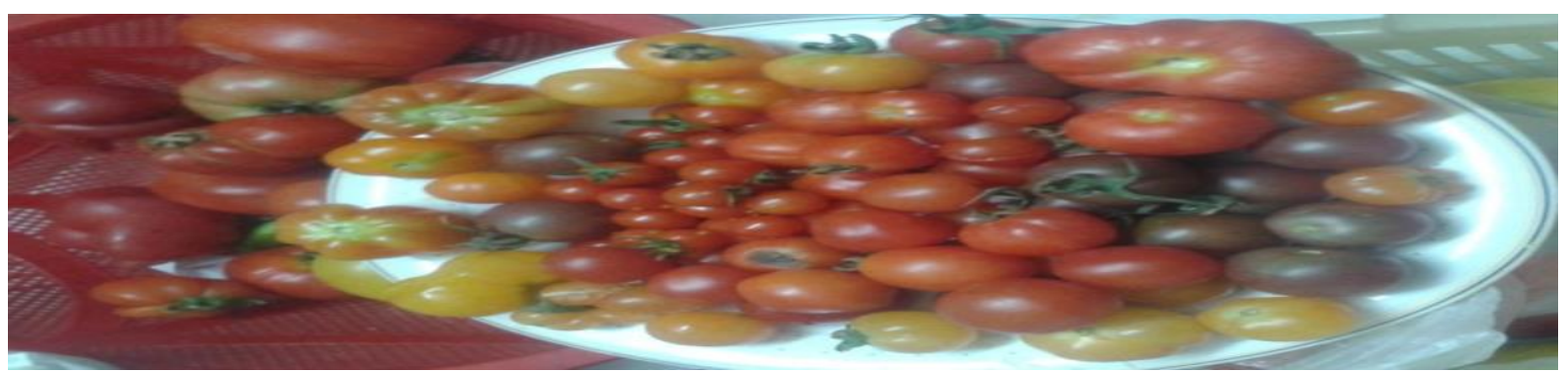

Figure 2. Fruit size and shape based differences in studied tomato genotypes 


\section{Cluster analysis}

Cluster analysis on the basis of 10 qualitative traits classified all the germplasm into five main clusters at linkage distance 1.75 . The dendrogram was constructed using the complete linkage method and presented in the (Fig. 3). Cluster I grouped 62 genotypes and was the second largest group having nearly $33 \%$ of the total population. Cluster II was the largest comprising of 87 genotypes which were $47 \%$ of the total population. The cluster III consisted of five genotypes (TH-10-50021, TH-10-5-0043, Tom 10, Burnely Fortune and Santa) which were $2.7 \%$ of the population and this was followed by cluster IV with 9 genotypes (Yellow Stuffer, Roman Candle, Striped Cavern, Yellow Round Tomato, Li Cun, TH-10-0018, TH-10-0035, A. Kosta Perchev, Vidin and S. Klave, Blagoevgrad) which were $5 \%$ of total population. Cluster V comprised of 22 genotypes. Accessions on a qualitative basis divided into different clusters are given in Table 7.

Intra-cluster differences were detected in all clusters except cluster- III having mostly similar traits in all five genotypes. The contributed variables in the clustering included leaves and fruits. Genotypes of cluster I was uniform for round shape and red color of fruits, horizontal leaf attitude, standard leaf type, few leaves under the first inflorescence and hairy stem with moderate dense foliage, short stem internode length, the light green color of immature fruit and small fruits. While mostly genotypes of cluster II had a round shape and red-colored fruits and pubescent stem with moderate large-sized fruits, green-colored immature fruit, short internode stem length, dense foliage, standard leaf type, drooping leaves and few leaves under the first inflorescence. Cluster III exhibited diversity for most qualitative traits and uniformity for the shape of the fruit, leaf attitude and number of leaves under the first inflorescence. Cluster IV was expressed to have no diversity for a number of leaves under the first inflorescence and leaf type. The maximum accessions of this cluster showed dense pubescent stem, intermediate stem internode length and moderate intermediate foliage density, horizontal leaf attitude, flattened shape, medium-sized fruits and greenish-white and yellow color of mature and immature fruits. Cluster $\mathrm{V}$ also displayed polymorphism for all traits and uniformity only for leaf type.

Tomato germplasm displaying diverse genetic character was used in this study. Various qualitative traits for vegetative and reproductive stages were sufficient to differentiate the tomato germplasm in addition to seedlings. Significant diversity for agro-morphological characters was also described in tomato by other researchers [37]. For plant description, qualitative traits are important and are prompted by the preference of consumers, natural collection and socioeconomic circumstances [38]. The fruit appearance of tomato is a dynamic factor of quality. Bai and Lindhout [39] reported a wide range of diversity in fruit shapes of tomato germplasm. The diversity found in germplasm was mostly due to genetics that accounts for variations. The development of inheritance for variation of fruit shape is determinate by nature [40].

Various other traits such as stem morphology [41], size of fruits [42], shape and color [43, 44] and locule number [45], bound to the similar pattern of inheritance. Genetic switch of qualitative characters through particular genes that are different forms of alleles condenses these traits relatively stable to the changes of surroundings therefore, no significant change was detected during two years for qualitative traits. The different genotypes had a diverse size of fruits at the commencement of maturity is correlated to cell number next to size [46]. The close relative of the cultivated tomato that is cherry tomato accessions showed very small fruits with round shapes only. Fruit shape, size and color are vital parameters for the quality of fruit. Maximum genotypes had red color fruits as compared to pink. This difference is because red fruits have yellow skin whereas pink has colorless skin. The red color was found to be different in the cultivars that are signed for lycopene concentration $[47,48]$. On the other hand by selecting an appropriate irrigation practice concentration of lycopene is improved [49-51]. 
Pure Appl. Biol., 9(1): 776-789, March, 2020

http://dx.doi.org/10.19045/bspab.2020.90084

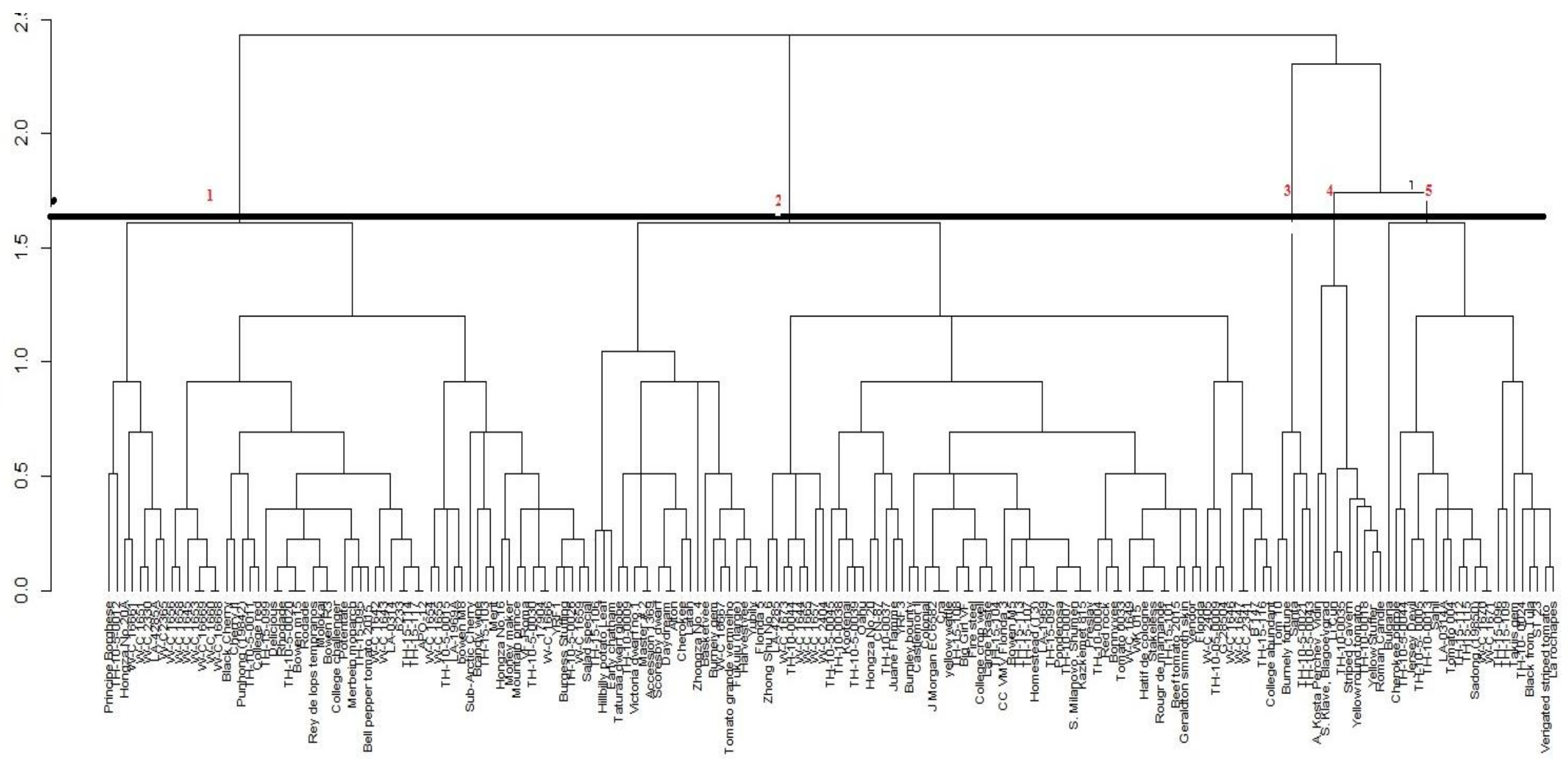

Figure 3. Dendrogram based on qualitative traits of 185 genotypes of tomato germplas 


\section{Conclusion}

The morphological diversity observed among different tomato genotypes could be associated with variation of factors. The morphological variations observed in tomato genotypes could be described as differences in environmental and genetic conditions. The nutrient status of the soil is a basic factor of climatic conditions that significantly contribute to the variances in the performances of the cultivar. Characterization of tomato germplasm at the seedling stage and qualitative traits of tomato plants is suggested for broadening the use of core collections so as to use more efficiently crop germplasm in minimum time.

\section{Authors' contributions}

Conceived and designed the experiments: A Hamid \& A Ghafoor, Performed the experiments: S Anjum, Analyzed the data:S Anjum, A Ghafoor \& RMM Naz, Contributed reagents/ materials/ analysis tools: A Hamid \& A Ghafoor, Wrote the paper: S Anjum \& RMM Naz.

\section{Reference}

1. Ambresh H, Lingaiah B, Renuka M \& Jyothi K (2017). Phenotypic and genotypic correlation coefficient studies in tomato (Solanum lycopersicum L.) for yield and quality traits. Inter J Curr Microbiol Appl Sci 6: 2287-2292.

2. Charfeddine G, Abdelkrim AB, Fakhfakh H, Salhi-Hannachi A \& Gorsane F (2016). SSR marker-assisted screening of commercial tomato genotypes under salt stress. Breed Sci 66: 823-830.

3. Peterson DG, Stack SM, Price HJ \& Johnston JS (1996). DNA content of heterochromatin and euchromatin in tomato (Lycopersicon esculentum) pachytene chromosomes. Genome 39: 7782.

4. Maria LSS, Marmiroli M, Maestri E \& Marmiroli N (2013). Genetic characterization of Italian tomato varieties and their traceability in tomato food products. Food Sci Nutr1: 54-62.
5. Dibaba MD (2016). Genetic diversity among tomato (Solanum lycopersicon L.) genotypes in Northern Ethiopia. Global J Plant Breed Genet 3: 239-247.

6. Peralta IE, Knapp S \& Spooner DM (2006). Nomenclature for wild and cultivated tomatoes. Tomato Genetics Cooperative Report 56: 6-12.

7. Larry R \& Joanne L (2007). Genetic resources of tomato. In: Razdan MK, Mattoo AK, eds. Genetic Improvement of Solanaceous Crops. Vol. 2. Tomato. Enfield, NH: Science Publishers. 25-76.

8. Foolad MR (2007). Genome mapping and molecular breeding of tomato. Inter $J$ Plant Genomics 52: 64-69.

9. Gonçalves LSA, Rodrigues R, Sudre CP \& Bento CS (2008). Genetic divergence among tomato accessions using RAPD markers and its comparison with multicategoric descriptors. Hort Sci 26: 364-370.

10. Kanneh SM, Osei MK, Akromah R \& Gyau J (2016). Generation means analysis of yield and yield components of earl generations of interspecific crosses of tomato (Solanum lycopersicum L.). Inter J Plant Breed and Genet 10: 98-103.

11. FAOSTAT (2016). Crop statistics database on the World Wide Web. http://app.fao.org./fao.stat.last (Accessed on 26-4-2018).

12. Afzal I, Munir F, Ayub CM, Basra SMA, HameedA \& Shah F (2013). Ethanol priming: an effective approach to enhance germination and seedling development by improving the antioxidant system in tomato seeds. Acta Scientiarum Polonorum. Hortorum cultus 12:129-137.

13. Ojo MA, Ibrahim OA \& Mohammed US (2009). Profitability and production function of small scale irrigated tomato production in Niger State, Nigeria. Continental J Agric Econ 3: 16-22.

14. Tam SM, Causse M, Garchery C, Burck H, Mhiri C \& Grandbastien MA (2007). The distribution of copia-type retrotransposons and the evolutionary history of tomato and 
related wild species. J Evol Biol 20: 10561072.

15. Jenkins JA (1948). The origin of the cultivated tomato. Econ Bot 2: 379-392.

16. Khan SA (2009). Screening of tomato cultivars against root-knot nematodes and their biological management. Ph.D Thesis, p: 152. Department of Plant Pathology, University of Agriculture, Faisalabad, Pakistan

17. Abdullahi MS\& Choji KB (2009). The origin and benefits of tomato as a home garden and commercial vegetable. Electr J Environ Agric Food Chem 8: 1156-1169.

18. Mazzucato A, Ficcadenti N, Marcello C, Mosconi P, Piccinini E, Sanampudi VRR, Sestili S \& Frarari V(2010). Genetic diversity and distinctiveness in tomato landraces. Sci Hort 125:55-62.

19. Gul R, Rehman HU, Khalil IH, Shah SMA\& Ghafoor A(2010). Hetrosis for flower and fruit traits in tomato (Lycopersicum esculentum Mill.). Afr J Biotechnol 9: 4144-4151.

20. Xu A, Haun Z, Ma C, Xiao E, Tian G, Zhang X, Tu J, FuT\& Zhang G (2010). Inheritance of seed color and molecular markers linked to the seed color gene in Brassica juncea. Mol Breed 25: 57-65.

21. Basunanda P, Radoev M, Ecke W, Friedt W, Becker HC \& Snowdon RJ (2010). Comparative mapping of quantitative trait loci involved in heterosis for seedling and yield traits in oilseed rape (Brassica napus L.). Theor Appl Genet 120: 271-281.

22. Ashfaq M, Khan AS, Khan SHU \& Ahmad $R$ (2012). Association of various morphological traits with yield and genetic divergence in rice (Oryza sativa). Int $J$ Agric Biol 14: 55-62.

23. IBPGR (1996). International Board for Plant Genetic Resources. Wageningen, the Netherlands.

24. Sneath PHA\& Sokal RP (1973). Numerical taxonomy, the principles, and practice of numerical classification. San Francisco, CA. 573pp.

25. Kaemmer D, Weising K, Beyermann B, Borner T, Epplen JT \& Kahl G(1995).
Oligonucleotide fingerprinting of tomato DNA. J Plant Breed 114: 12-17.

26. Rasmussen K\& Rasmussen J (2000). Barley seed vigor and mechanical weed control. Weed Res 40: 219-230.

27. Olivera PD \& Steffenson BJ (2009). Aegilops sharonensis: Origin, genetics, diversity, and potential for wheat improvement. Bot 87: 740-756.

28. Rafalski JA (2009). Association genetics in crop improvement. Curr Opin Plant Biol 13: 174-180.

29. Kamenetzky L, Asís R, Bassi S, de Godoy F, Bermúdez L, Fernie AR, Van Sluys MA, Vrebalov J, Giovannoni JJ, Rossiand M \& Carrari F(2010). Genomic analysis of wild tomato introgressions determining metabolism and yield associated traits. Plant Physiol 152: 17721786.

30. Cruz MD, Moura CL, Gonçalves LSA, Sudré CP, Rodrigues R, Júnior ATA \&Pereira T. NS (2010). The Grower's algorithm on the estimate of genetic diversity in chili pepper germplasm. Hort Brasil 28: 155-161.

31. Rizvi A, Ashraf M\& Ghafoor A (2013). Genetic divergence for seedling traits in tomato (Solanum lycopersicum). Int J Agri Biol 15: 451-457.

32. Muller CH (1940). A revision of the genus Lycopersicon. USDA Misc. Publication, 328: 29pp.

33. Mochizuki T \& Kamimura S (1985). Early screening of high pigment lines of tomato at the cotyledon stage using yellow film. Bull vegetable ornamental crops Research Station. Japan, 5: 3-25.

34. Smýkal P, Horáèek J, Dostálová R \& Hýbl $M$ (2008). Variety discrimination in pea (Pisum sativum L.) by molecular, biochemical and morphological markers. $J$ Appl Genet 49: 155-166.

35. Ghafoor A \& Arshad M (2008). Multivariate analysis for quantitative traits to determine the genetic diversity of black gram (Vigna mungo L.) Hepper germplasm. Pak J Bot 40: 2307-2313. 
36. Hafen L \& Stevenson EC (1956). Natural cross pollination in tomato using several male-sterile mutants. Proceedings of American Society for Horticultural Science 68: 433-436.

37. Evgenidis G, Traka-Mavrona E \& Koutsika-Soitiriou M (2011). Principal component and cluster analysis as a tool in the assessment of tomato hybrids and cultivars. Inter J Agron 7:1-7.

38. Ghafoor A, Sharif A, Ahmad Z, Zahid MA \& Rabbani MA (2001). Genetic diversity in blackgram (Vigna mungo L. Hepper). Field Crops Res 69: 183-190.

39. Bai $Y$ \& Lindhout P (2007). Domestication and breeding of tomatoes: what have we gained and what can we gain in the future? Annals of Bot 100: 10851094.

40. Paran I \& Van der Knaap E (2007). Genetic and molecular regulation of fruit and plant domestication traits in tomato and pepper. J Exper Bot 58: 3841-3852.

41. Coaker GL, Meulia T, Kabelta EA, Jones AK \& Francis DM (2002). A QTL, controlling stem morphology and vascular development in Lycopersicon esculantum $\mathrm{x}$ Lycopersicon hirsutum (Solanaceae) crosses is located on chromosome 2. Am J Bot 89: 1859-1866.

42. Nesbitt TC \& Tanksley SD (2002). Comparative sequencing in the genus Lycopersicon: implications for the evolution of fruit size in the domestication of cultivated tomatoes. Genet 162: 365379.

43. Frary A, Doganlar S, Frampton A, FultonT, Uhlig J, Yates H\& Tanksley $\mathrm{S}(2003)$. Fine mapping of quantitative trait loci for improved fruit characteristics from Lycopersicon chmielewskii chromosome 1. Genome 46: 235-243.
44. Emami A\& Eivazi AR (2013). Evaluation of genetic variations of tomato genotypes (Solanum lycopersicum L.) with multivariate analysis. Inter J Sci Res in Environ Sci 1: 273-284.

45. Barrero LS \& Tanksley SD (2004). Evaluating the genetic basis of multiple locule fruit in a broad broad cross section of Tomato cultivars. Theor Appl Genet 109: 669-679.

46. Cheniclet C, Rong WY, Causse M, Frangne N, Bolling L, Carde JP \& Renaudin JP(2005). Cell expansion and endore duplication show a large genetic variability in pericarp and contribute strongly to tomato fruit growth. Plant Physiol 139: 1984-1994.

47. Brandt S, Pék Z, Barna E, Lugasi A \& Helyes L(2006). Lycopene content and color of ripening tomatoes as affected by environmental conditions. J Sci Food Agri 86: 568-572.

48. Helyes L, Pék Z \& Lugasi A (2006). Tomato fruit quality and content depend on stage of maturity. Hort Sci 41: 14001401.

49. Rosales MA, Ruiz JM, Hernandez J, Soriano T, Castilla N \& Romero L (2006). Antioxidant content and ascorbate metabolism in cherry tomato exocarp in relation to temperature and solar radiation. J Sci Food Agri 86: 1545-1551.

50. Toor RK, Savage GP \& Lister CE (2006). Seasonal variations in the antioxidant composition of greenhouse grown tomatoes. J Food Composition Analysis 19: 1-10.

51. Dumas Y, Dadomo M, Di Lucca G \& Grolier P (2003). Effects of environmental factors and agricultural techniques on antioxidant content of tomatoes. $J \mathrm{Sci}$ Food Agri 83:s 369-382. 